\title{
The Relational Thinking Process of Secondary School Student with High Mathematical Ability in Solving Mathematics Problem
}

\author{
Ahmad Zakaria \\ Mathematics Education Study Program, Faculty of \\ Mathematics and Natural Sciences \\ Universitas Negeri Surabaya, Surabaya, East Java, \\ Indonesia \\ ahmadzakaria16070785016@mhs.unesa.ac.id
}

\author{
Mega Teguh Budiarto, Raden Sulaiman \\ Department of Mathematics, Universitas Negeri \\ Surabaya, Surabaya, East Java, Indonesia \\ megatbudiarto@unesa.ac.id, \\ sulaimanraden@yahoo.com
}

\begin{abstract}
This research is aimed to describe the process of relational thinking of junior high school student with high level a ability in solving mathematical problems. In this qualitative research, data collection techniques are performed by using tests and interview. The subject of this research is only one female student of the eighth grade. The main instruments used are the mathematical ability test, problem-solving test (PST), and interview guidelines as a supporting instrument. The data analysis is worked out with data reduction, data presentation and conclusion. The result of the research shows that the way of student's relational thinking can help to solve the problems correctly. The subject of this research relates the information she knew with the knowledge she has about Pythagorean Theorem and velocity formula. She builds a relation between the problem of understanding (relation between the element and information in the problem) and the knowledge she has (the usages of the Pythagorean Theorem and velocity formula). Then, she used the same way as planned to complete the problem-solving task. For the last activity, she reads and makes a correction on the steps she has done to ensure that her answer is correct.
\end{abstract}

Keywords-Relational Thinking, Problem-solving, Math Ability

\section{INTRODUCTION}

Mathematics is one of the disciplines that capable to improve the ability to think and argue in solving problems related to structured ideas that are logically arranged to develop the thinking skills. Kiziltoprak and Kose argue that "Mathematics is one of the most important tools for the development of thinking skills that individuals need to solve their daily life problems" [1]. Thinking is a dynamic process that can be described by process or path [2].

The thinking process of a person in solving problems may vary because everyone has different ways to organize and process information as well as experience to deal with the problem. One type of the thinking process is relational thinking. Doumas and Hummel said, "Relational thinking is the ability to understand analogies between seemingly different objects or events and the ability to apply abstract rules in new situations" [3]. Thus, relational thinking is a mental process characterized by building the connection between elements of information provided with previous knowledge and knowledge of the properties or structures of mathematics to solve mathematical problems.

Hejny et al provide the characteristics of the problemsolving procedure on relational thinking as follows: (1) creating an image in solver's mind about the problem as a whole, (2) analyzing to find the core structure of the problem, (3) finding key elements or relations in the problem that will give an insight to the solver the given and the unknown elements, (4) constructing a completion strategy after the elements or relationships are found [4].

The importance of relational thinking is to understand how students connect the information from the problem with the concepts they have to solve mathematical problems. The importance of relational thinking in mathematics is also expressed by Napaphun "Relational thinking skill can support the development of algebraic reasoning while at the same time improve the learning and understanding of arithmetic" [5].

Math problem-solving skills are not easy for students to do. Pimta et al argue that "problem-solving is considered as the heart of math learning because the skill is not only for learning the subject, but also for emphasizing on the development of thinking skill method" [6]. Each individual has its own distinctive features in solving mathematical problems so that each individual is different from each other.

The difference is caused by several factors, one of which is the mathematical ability. Uno states that an ability refers to a person's performance in his work that can be seen from his thoughts, behavior, and attitudes [7]. The purpose of this study is to describe the relational thinking process of secondary school students with high mathematical ability in solving mathematical problems. 


\section{METHOD}

This research constitutes a qualitative one in which the technique of data gathering was carried out with test and interview. The subject of this research is a female student of the eighth grade and the main instrument is the researcher himself, supported with Mathematical Ability Test (MAT), Problem-solving Test (PST), and an interview guideline as a supporting instrument. MAT, PST and the interview guidelines are validated by two lecturers of Faculty of Mathematics Education and a mathematics teacher. The validated PST is called PST 1, while PST 2 is the equivalent to PST 1 which is used as triangulation. Besides being validated, MAT and PST have tested their readability by 5 students who aren't subjects of this research. At the time of selecting the subjects, 26 students are provided MAT test to identify their mathematical ability.

Then with regard to gender, a female student with a high level of mathematical ability is selected. Then, the subject will be given PST problems and continued to the interview to find out the students' rational thinking process. Data analysis is worked out with data condensation, data presentation and conclusion.

\section{RESULTS AND DISCUSSION}

This study aims to describe the relational thinking process of secondary school students in solving mathematical problems based on the level of mathematical ability.

TABLE I. SUMMARY OF STUDENT RELATIONAL THINKING WITH HIGH MATHEMATICAL ABILITY IN MATHEMATICAL PROBLEM-SOLVING

\begin{tabular}{|c|c|}
\hline \multirow{2}{*}{$\begin{array}{c}\text { Polya's Solution } \\
\text { Step }\end{array}$} & Description of Relational Thinking \\
\hline & Students with High Math Ability \\
\hline $\begin{array}{l}\text { Understanding } \\
\text { the Problem }\end{array}$ & $\begin{array}{l}\text { - Write down what is known and what is asked } \\
\text { as clear as possible. } \\
\text { Connect the known information to the } \\
\text { Pythagoras Theorem as well as velocity } \\
\text { formula and the known information to the } \\
\text { questionable problem. }\end{array}$ \\
\hline Preparation Plan & $\begin{array}{l}\text { Connect each step to be used in solving the } \\
\text { problems such as: draw sketches first in } \\
\text { accordance with the information contained in the } \\
\text { question, use Pythagorean Theorem to determine } \\
\text { an unknown value and use the velocity formula to } \\
\text { determine the time spent. }\end{array}$ \\
\hline $\begin{array}{l}\text { Implementation } \\
\text { Plan }\end{array}$ & $\begin{array}{l}\text { - Draw sketches by using compass points to } \\
\text { simplify mapping of the houses according to } \\
\text { the available information. } \\
\text { - Use the information contained in the question } \\
\text { and then connect it with Pythagorean Theorem, } \\
\text { velocity formula and counting operations to } \\
\text { determine what is unknown. } \\
\text { - Use the Pythagorean Theorem, velocity } \\
\text { formula and counting operations to determine } \\
\text { what is unknown. }\end{array}$ \\
\hline Conclusion & $\begin{array}{l}\text { - Read and re-correct the steps that have been } \\
\text { done so that the subject is sure that her answer } \\
\text { is correct. } \\
\text { - Rationalize the answer with the initial problem } \\
\text { is not conducted by the student. }\end{array}$ \\
\hline
\end{tabular}

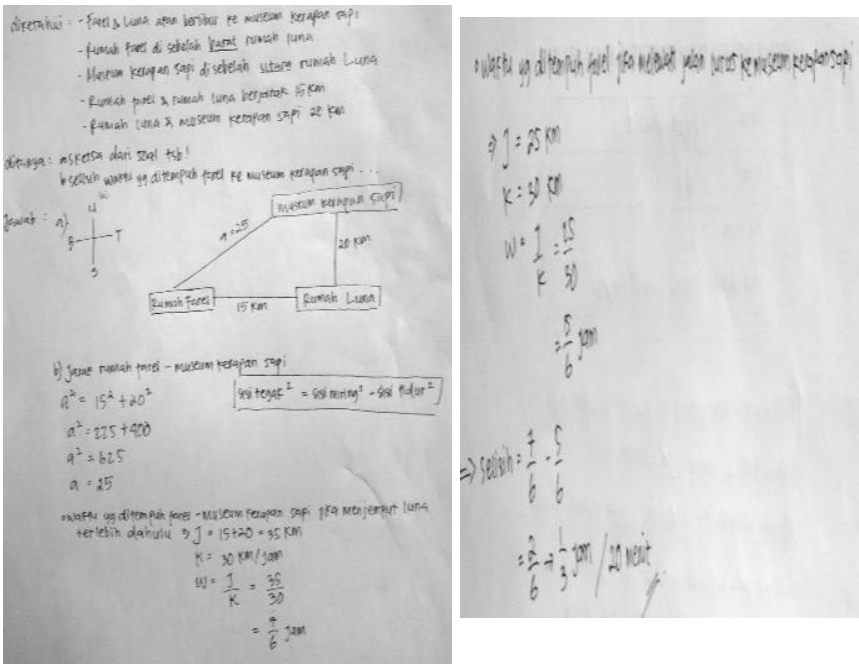

Figure 1. Result of PST

Based on the research that has been done, it was found that the relational thinking profile of the subject was when she tried to understand the problem she wrote down what is known and what is asked completely in the indicator panel. The subject explained the relationship between the elements/ concepts/ information that exist on the problem with what the student had. In relation to the given problem, the student connected the known information with her prior knowledge of the Pythagoras Theorem as well as the velocity formula and the known information to the question asked. The subject explained the interrelationships in each element and between the elements, which is to relate the known information to the Pythagorean Theorem as well as the velocity formula, and to explain the relationship of the whole problem, i.e. to mention the known information in the problem to answer the question asked. This is according to Baiduri's research, the relational thinking profile of female subjects with high math skills to understand the problem is by integrating the information in questions and prior knowledge (symbols) [8].

The subject wrote down the steps that would be used to solve the problem. The subject's understanding of the problem is obviously related to the known information. Whereas prior knowledge is related to the selection of theorems/ formulas used in planning the problem-solving. The theorem/ formula used was the Pythagoras theorem and the velocity formula. Understanding of symbols, traits or rules to determine the unknown distance and time could be seen when the subject sketches. The result of the sketch was a right triangle model, so to determine the distance was by using Pythagoras Theorem, while to determine the travel time was by using velocity formula. The subject further used a subtraction operation to calculate the time difference asked in the question. This is in accordance with the opinion of Carpenter et al which states that relational thinking involves the use of the basic properties of numbers and operations to change the mathematical expressions rather than counting the answers that follow the sequence of procedures [9]. The subject also 
built a relationship between an unknown number and a count operation. The subject understood well the purpose of using the subtraction operation to calculate the difference in distance and time. The subjects also used the Pythagoras Theorem and the velocity formula to find the unknown distance and time.

In the execution of the problem-solving plan, the subject was able to associate between unknown numbers using the Pythagoras Theorem as well as velocity formula with the power relations by using the counting operation. This could be seen when the subject solved a given problem when the subject used the same method as planned: using Pythagorean Theorem and velocity formula, as well as the count operation to complete problem-solving tasks (PST) 1 and problemsolving tasks (PST) 2. According to Molina and Ambrose's opinions, relational thinking is associated with many different relationships that children do in recognizing, building between and within numbers, expression and operation [10]. In the process of re-examining the problem-solving, the subject read and corrected the steps that have been done so that the subject was sure the answer is correct. However, the activity of rationalizing the answer with the problem was not done by the subject.

\section{CONCLUSION}

Based on the level of problem-solving by Polya, the relational thinking process of secondary school students with high mathematics skills when understanding problems can be seen in their steps in trying to understand the problem i.e. when the subject is connected between the known information with the Pythagorean Theorem and the velocity formula and when the subject describes the relationship between the known information with all existing problems [11]. This is intended to be able to answer the questions that exist and to do it correctly. Furthermore, at the step of arranging a plan of finishing problems, the subject connects each step which will be used in solving problems like drawing sketch, agreeing with what has been known in the question, applying Pythagorean Theorem to find the unknown value and taking velocity formula to define the running time. Whereas at the step of problem-solving, the subject sketches by using directions to know the locations of houses based on the information easily. To use the available information in the questions and make a connection with Pythagorean Theorem and velocity formula as well as counting operation to define what has not yet been known. At the step of rechecking the problem-solving, the subject will only make a brief reading and correction without re-counting steps s/he has done to solve the problems. Nevertheless, the subject is expected to make a rational answer with the existed problem.

\section{References}

[1] A. Kizıltoprak and N. Y. Kose, "Relational thinking: The bridge between arithmetic and algebra", IJEE, vol. 10, no. 1, 2017.

[2] S. Suryabrata, Psikologi pendidikan Ed. 5, Jakarta: Rajawali Pers, 2013.

[3] L. A. A. Doumas and J. E. Hummel. Approaches to Modelling Human Mental Representations: What Works, What Doesn't, and Why?, The Cambridge Handbook of Thinking and Reasoning: Cambridge. University Press, 2005.

[4] M. Hejny, D. Jirotkova, and D. Kratochvilova, "Early Conceptual thinking", Proceedings $30^{\text {th }}$ Conferences of the International Group for the Psychology of Mathematics Education, vol. 3, pp. 289-296, 2006.

[5] V. Napaphun, "Relational thinking: Learning arithmetic in order to promote algebraic thinking", Journal of Science and Mathematics Education in Southeast Asia, vol. 35, no. 2, pp. 84-101, 2012.

[6] S. Pimta, S. Tayruakham, P. Nuangchalerm, "Factor Influencing Mathematics Problem-solving Ability of Sixth Grade Student", Journal of social Sciences, vol. 5, no. 4, pp. 381-385, 2009.

[7] H. B. Uno, Orientasi Baru dalam Psikologi Pembelajaran, Jakarta: Bumi Aksara, 2008.

[8] Baiduri, "A Relational Thinking Process of Elementery School Students with High Capability", Journal of Educational and Developmental Psychology, vol. 4, no. 2, 2014.

[9] T. P. Carpenter, M. L. Frunke, Madison, L. Levi, and J.K. Zeringue, "Algebra in Elementary School: Developing Rational Thinking", ZDM, vol. 37, no. 1, pp.53-59, 2005.

[10] M. Molina and R. Ambrose, "From an operation to a relational conception of the equal sign: Thirds grades' developing algebraic thinking", Focus on Learning Problems in Mathematics, vol. 30, no. 1, pp. 61-80, 2008.

[11] G. Polya, How to Solve it. $2^{\text {nd }} E d$, Princeton University Press, 1973. 